\title{
Substantiating a technique to process hard rock involving extraction of valuable components and use of wastes to form mesorelief
}

\author{
Kateryna Babii ${ }^{1, *}$, Oleksandr $\mathrm{Ikol}^{1}$, and Yevhenii Malieiev ${ }^{1}$ \\ ${ }^{1}$ Institute of Geotechnical Mechanics named by N. Poljakov of National Academy of Sciences of \\ Ukraine, 49005, Dnipro, Simferopolska Str., 2a, Ukraine
}

\begin{abstract}
A technique to process rock mass from hard-rock technogenic media has been developed; it is aimed at recovery of mineral losses, restoration of the environment at the territory of mining enterprises by means of rock mass extraction, its processing and redistribution for the purposes of land recultivation and landscape restoration. Classification of dry ore-containing hard rocks of dumps has been developed; that has made it possible to improve technological scheme of the processing of rock mass from technogenic media, emphasize its variants of use, and specify the required facilities and their productivity. Scientific value of the paper is in determining the effect of changes in the losses in pre-processing dry wastes upon the yield of industrial product and wastes; the effect has demonstrated that the yield of industrial product is in polynomial dependence upon the pre-processing losses while yield of tailings is in the power dependence. Practical implications of the paper are in the fact that the proposed method helps form mesorelief with the properties close to the natural one. The method involves restoration of the initial landscape with the help of opening hard rocks followed, completed by laying waterbearing and potentially fertile layers.
\end{abstract}

\section{Introduction}

Open-pit mining is impossible without opening operations; moreover, further mineral processing is required to obtain commercial minerals. As a result, certain technogenic media surrounds any mining enterprise in the form of internal and external dumps, storages, and tailing facilities. The environment experiences certain changes owing to the increase in volumes and areas of technogenic media effecting it: fine rock particles enter the atmosphere resulting in dust storms; productive land areas are occupied with waste storages; both hydrological and hydrogeological parameters of such areas change as well. One of the tendencies to control the technogenic areas is their processing with the recovery of losses of both minerals and associated products; that makes it possible to redistribute rock mass volumes and use wastes for recultivation and mesorelief development or restoration.

*Corresponding author: babiyev@i.ua 
The available technogenic media (dumps, storages of intermediate and potential raw material, tailing facilities) contain considerable mineral deposits of technogenic origin. They are formed while extracting mineral raw material since the extraction technique is not perfect; that results in significant mineral losses and dilution. Nowadays, numerous scientists are studying that problem; moreover, different methods to reduce the losses have been already developed. However, despite the considerable scientific and technical achievements, dumps and tailings at mining and concentration plants continue to accumulate numerous wastes of minerals and associated products.

Studies concerning the technology to extract and process rock mass have proved that following ores are sent into dumps:

a) commercial ores from the stoping faces where deposit structure is characterized by complex geological conditions, i.e. losses. Those mining conditions are controlled by special services with corresponding recording and deducting of the lost reserves;

b) non-commercial, they are not subject to record. That concerns following mineral groups:

- mineral with non-commercial composition,

- ore interlayers,

- ore nip into the barren rock,

- mixture of mineral raw material with the rock while opening by means of blasting operations etc.;

c) oxidized ores which should be stored in a separate storage or dump as a potential mineral raw material;

d) dry wastes of a processing plant after preliminary mineral dressing including aggregates; they are losses as well.

\section{Dependence of ore losses during extraction upon mining and geological parameters}

Mineral losses and dilution while mining are determined by following parameters of openpit mining operations [1]:

- mining (complex deposit structure, amount of "enclosing rock-ore" contact zones, their visual differences, dip angle of seams, coal bands in them, variety of geological minerals, thickness of barren interlayer, noncommercial ores etc.);

- technological (bench height, width of excavator pass, parameters of the production block, cut-off grade of the mineral, direction of the block development relative to the contact zone area, possibility to apply selective extraction etc.);

- technical (capacity of excavator buckets, means of transport, overall dimensions of the equipment etc.).

Paper [1] studies thoroughly mineral losses and dilution depending upon the parameters of open-pit mining. According to the data obtained before, mineral losses are in direct proportion to the bench height and thickness of ore deposit in it, direction of "enclosing rocks-ore" contact zone, and natural dip angle. Those studies were developed further as for the effect of technical characteristics of the excavating machinery.

The available methods to increase ore quality within the stoping face have been analyzed. It has been determined that selective extraction and mineral blending are the most popular techniques during the production process. However, selective extraction was rather efficient in the $1980 \mathrm{~s}-1990 \mathrm{~s}$, when excavators with the bucket capacity of $3-5 \mathrm{~m}^{3}$ and even sometimes $8 \mathrm{~m}^{3}$ (in terms of dump truck capacity of 45-75 t) were used. In the 2000s, in terms of iron-ore open pits, excavators with bucket capacity of 8-12 $\mathrm{m}^{3}$ (since dump truck capacity has increased up to 110-150 t) are applied while, in terms of Kryvbas iron-ore open pits, the project works are going to use excavators with the capacity of $20 \mathrm{~m}^{3}$. Two 
excavators with bucket capacity being $27 \mathrm{~m}^{3}$ operate already in iron-ore open pit of Sokolovsk-Sarbaisk Mining Production Association [2]. That tendency as for the growth of the bucket capacity of excavating machinery results in the increased ore mass dilution or considerable losses which is demonstrated in Figure 1 depending on the inclination angle of the deposit $\alpha$.

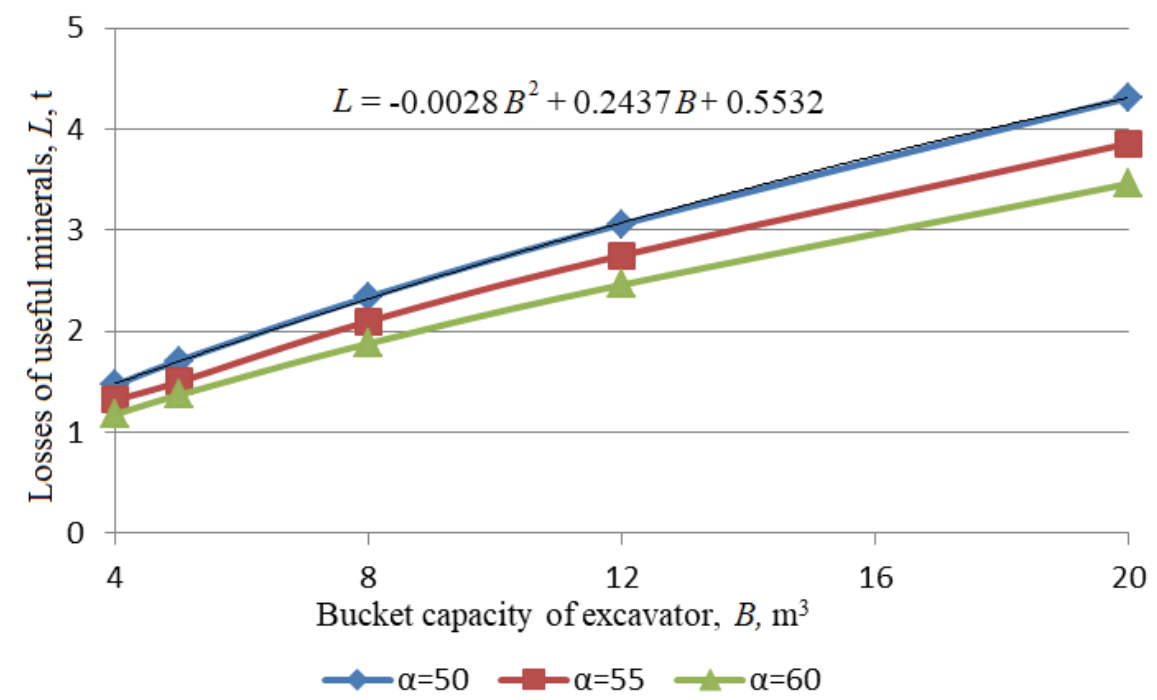

Fig. 1. Dependence of ore losses upon bucket capacity.

Studies have demonstrated that ore losses in an open pit depend polynomially upon technical characteristics of the equipment being directly proportional to the contact zone angle and inversely proportional to the processing volumes. Mineral losses are accumulated in different technogenic media.

\section{Methods to recover mineral losses from technogenic media}

Dumps, storages, sludge tanks and tailing facilities accumulate technogenic media in the form of losses and associated minerals which may be extracted. To do that, rock mass should be processed to extract valuable components. Preliminary rock mass dressing is a prospective processing technique. There are several ways of preliminary dressing differing in dressing methods involving the equipment based on the application of specific chemical and physical properties of rock: magnetic, gravitational, gravitational-magnetic, radiometric, and electrical.

Currently, much attention is paid to the development of radiometric methods which use different radiation to distinguish valuable components in the rock pieces (natural radioactivity, light, X-ray, nuclear, electromagnetic radiation of various ranges). Methods of magnetic dressing are based on the difference between magnetic properties of the components being separated; they are widely used to process ores of ferrous, rare, and nonferrous metals. Material separation basing upon magnetic properties is performed mostly in constant magnetic field. Depending upon the peculiarities of technological processes, it can be mechanical (proper separation) or physicochemical and chemical (thermal and thermochemical adhesion). While determining the technique for preliminary dressing, one should consider rock mass lumpiness, physical properties (magnetic sensitivity or density) etc. 
In terms of iron ores, all the mentioned dressing techniques can be used. However, productivity of a production complex is still the basic parameter during their application. Radiometric, electrical, and gravitational methods demonstrate good results during semi-production testing but they do not suit for large production capacities. Practice of iron ore processing shows that magnetic method is the most efficient one among dry preparation techniques. Correspondingly, there are different facilities used at dressing plants of mobile separation complexes.

\section{Method of mineral extraction from technogenic media}

A method has been developed to process hard rock mass from technogenic media to recover mineral losses and improve environmental conditions at the territories of mining enterprises by extracting rock mass, its processing and redistribution to recultivate lands and restore landscapes.

Recently, advanced facilities have been developed: separators for coarse-crushed rock mass; impact-centrifugal crushers and mills which provide both fine crushing and cleavage within the point of rock aggregation; separators for medium- and fine-crushed rock mass with high induction equipped with permanent magnets based on $\mathrm{Nd}-\mathrm{Fe}-\mathrm{B}$ or $\mathrm{Sm}-\mathrm{Co}$ alloys.

Process of segregation while rock mass dumping is the peculiarity of the formation of both technogenic media and deposits in them. When dumps are constructed by dump trucks or a stoker, the mass segregation in terms of lumpiness takes place due to the fact that large lumps with higher potential and kinetic energy roll down to the structure base. Thus, finer mass remains within the upper layers of the dump making it possible the extract it selectively and process without additional crushing.

A technique of rock mass extraction and processing involves sequential performance of such technological processes as excavation, transportation, screening, crushing, and dressing. Figure 2 demonstrates general scheme of rock mass processing in terms of dumps.

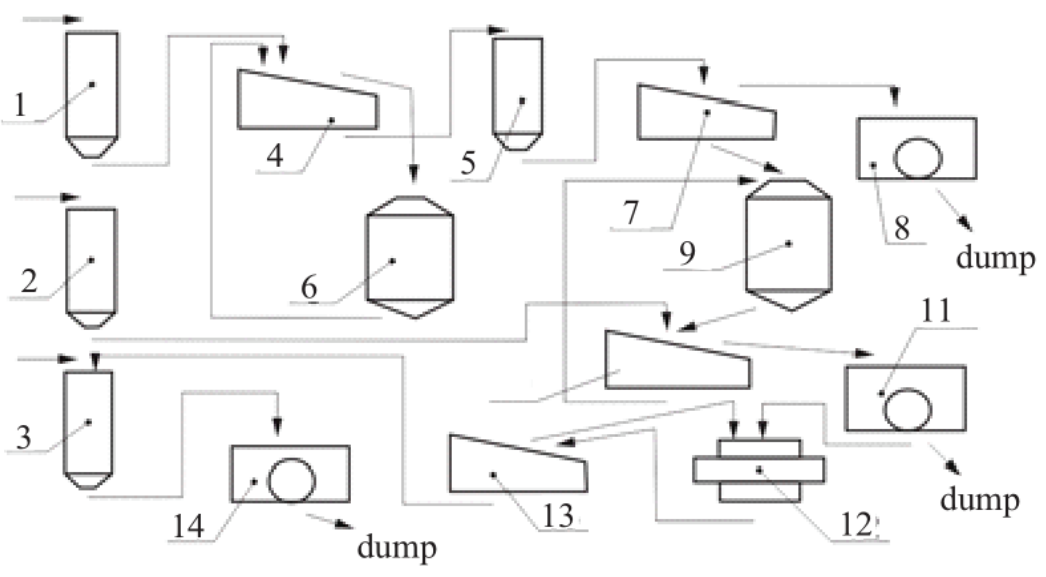

Fig. 2. Technological scheme of dump rock-mass processing: 1 - bunkers or storages for the lowerlayer dump mass; 2 - bunkers or storages for the upper-layer dump mass; 3 - bunkers or storages for fine-crushed mass; 4 - screens to separate coarse-crushed mass; 5 - bunkers or storages for coarsecrushed rock mass; 6 - coarse crushers; 7 - screens to separate medium-crushed mass; 8 - separators for coarse-crushed rock mass; 9 - medium crushers; 10 - screens to separate fine-crushed mass; 11 advanced separators for medium-crushed rock mass; 12 - fine crushers; 13 - screens to separate finecrushed mass; 14 - advanced separators for fine-crushed rock mass. 
In terms of selective extraction, rock mass, according to its lumpiness, is fed from the lower layers to bunkers or storages 1; rock mass from the upper layers is fed into bunkers or storages 2. If there is fine-crushed mass, it is sent into bunkers or storages 3.

Sequence of the processing is as follows: rock mass comes from bunkers (or storages) 1 onto screens 4 for coarse-crushed mass separation. Then, through product is sent to bunkers (or storages) 5 for coarse-crushed rock mass and plus material is fed into coarse crushers 6 which products come onto screens 4 with closed cycle.

Rock mass comes from bunkers (or storages) 5 onto screens 7 for separation of medium-crushed mass; then, plus material is sent to separators 8 for coarse-crushed mass and through product is supplied into bunkers (or storages) 2. Barren mass is sent from separators 8 back to the dump or for relief recultivation and landscape restoration while ore inclusions are supplied to medium crushers 9 which product is sent to bunkers (or storages) 2. Rock mass is sent from bunkers (or storages) 2 onto screens 10 to separate fine-crushed mass. Plus material is supplied onto advanced separators 11 for medium-crushed rock mass while through product is sent to bunkers (or storages) 3 . Wastes of preliminary processing are sent from separators 11 back to the dump to be used for recultivation or as building material; ore portion is supplied onto crushers 12. After those crushers, the product is sent to screens 13, plus material is supplied again into the crushers for final closed cycle while through product is fed into bunkers (or storages) 3. From there, the mass is supplied onto advanced separators 14 for fine-crushed mass; further, ore portion is sent for processing at a dressing plant and barren mass is sent back to the dump or used for relief recultivation or other purposes.

Use of production processes and facilities in terms of the proposed technological scheme depends upon the rock type, rock mass value, lumpiness etc. Thus, classification of ore-containing dry hard rock of dumps has been proposed; the classification will make it possible to improve technological scheme to process rock mass from technogenic media of hard rock, to specify variants of its use, and to define the required equipment and its productivity. Classification of hard dry dump rock is as follows:

a) in terms of its origin

1) from an open pit:

- opening rocks from the "ore-enclosing rock" contact zone;

- rock mass with ore interlayers;

- orpening rocks with ore deposit nip-out;

- oxidized quartzites;

2) from a dressing plant:

- wastes of medium-crushed rock separation;

- wastes of fine-crushed rock separation;

b) in terms of the reserves purposes:

- commercial;

- non-commercial;

c) in terms of mineral type:

- high-quality;

- poor-quality;

- oxidized;

d) in terms of rock mass lumpiness:

- the one requiring coarse crushing $(300-400) \div 1500 \mathrm{~mm}$;

- coarse-crushed $(50-100) \div(300-400) \mathrm{mm}$;

- medium-crushed $(3-20) \div(50-100) \mathrm{mm}$;

- fine-crushed $(3-20) \mathrm{mm}$;

e) in terms of specific magnetic sensitivity:

- $\quad$ strongly magnetic with specific magnetic sensitivity $>400000 \mathrm{~m}^{3} / \mathrm{kg}$; 
- weakly magnetic with specific magnetic sensitivity $(750-10) \times 10^{-8} \mathrm{~m}^{3} / \mathrm{kg}$.

While determining a technological scheme for coarse rock, one should take into consideration that radiometric separators used for that purpose are characterized by low productivity (up to $70 \mathrm{t} / \mathrm{hr}$ ) while magnetic ones are characterized by the output of up to $800 \mathrm{t} / \mathrm{hr}$. However, any preliminary dressing used for rock mass from technogenic media (dumps, storages, and tailing facilities) results in the extraction of certain amount of industrial product with commercial content of a valuable component which is sent to a dressing plant:

$$
Q_{P}=Q_{o . p .}+Q_{o . r .}^{p . d .}, \mathrm{t}
$$

where $Q_{P}$ - productivity of dressing plant as for crushed ore, t; $Q_{o . p .}-$ open pit output, t; $Q_{\text {o.r. }}^{\text {p.d. }}$ - productivity of the preliminary dressing complex as for industrial product, $\mathrm{t}$.

Distribution of rock mass volumes while preliminary dressing depends upon technical and technological parameters of mining as well as upon qualitative characteristics of the material. Volume of the industrial product extraction with valuable component $Q_{o . r .}^{\text {p.d. }}$ is determined by the yield of valuable component in the extracted magnetic product $\gamma_{v . c .}^{p . d .}$.

$$
Q_{o . r .}^{p . d .}=Q_{o . r .} \cdot \gamma_{v . c .}^{p . d .}, \mathrm{t}
$$

where $Q_{\text {o.r. }}$ - rock mass volume being subject to preliminary dressing, t.

Productivity of the preliminary dressing complex is defined by qualitative indices of the rock mass before and after dressing (according to the general basics of dressing [3]):

$$
\gamma_{\text {v.c. }}^{p . d .}=\frac{\alpha-\theta_{p . d .}}{\beta_{p . d .}-\theta_{p . d .}},
$$

where $\alpha$ - magnetite iron content in the initial raw material, $\% ; \theta_{p . d .}-$ magnetite iron content in pre-dressing tailings, $\% ; \beta_{\text {p.d. }}$ - magnetite iron content in the magnetic product after pre-dressing, $\%$.

In its turn, yield of pre-dressing dry wastes is determined by dependence

$$
Q_{\text {d.w. }}=Q_{\text {o.r. }}-Q_{\text {o.r. }}^{\text {p.d. }} \frac{\alpha-\theta_{p . d .}}{\beta_{p . d .}-\theta_{p . d .}}, \mathrm{t} .
$$

According to the obtained analytic dependences (2)-(4), effect of qualitative characteristics of mineral raw material upon the pre-dressing complex productivity has been analyzed. Dependence of the pre-dressing complex productivity (industrial product yield) upon qualitative indices of mineral raw material has been identified: it is in linear dependence upon the valuable component content in the initial mineral mixture and in polynomial dependence upon the valuable component content in the output raw material.

At the same time, rock mass distribution in terms of industrial product and dry waste for further recultivation are defined by the dependences upon the losses of a valuable component and its content in the pre-dressing wastes (Fig. 3).

Pre-processing of technogenic raw material with valuable components results in following:

- mining enterprise has additional increment of ore mass to its dressing plant at the expense of obtaining $Q_{o . r .}^{\text {p.d. }}$ industrial product from the preliminary dressing complex; 
- volume of technogenic object per volume of mineral extraction decreases. Moreover, rock processing (screening, crushing, re-excavation) helps obtain additional products from the re-dressing wastes in the form of building material or materials for relief recultivation and restoration.

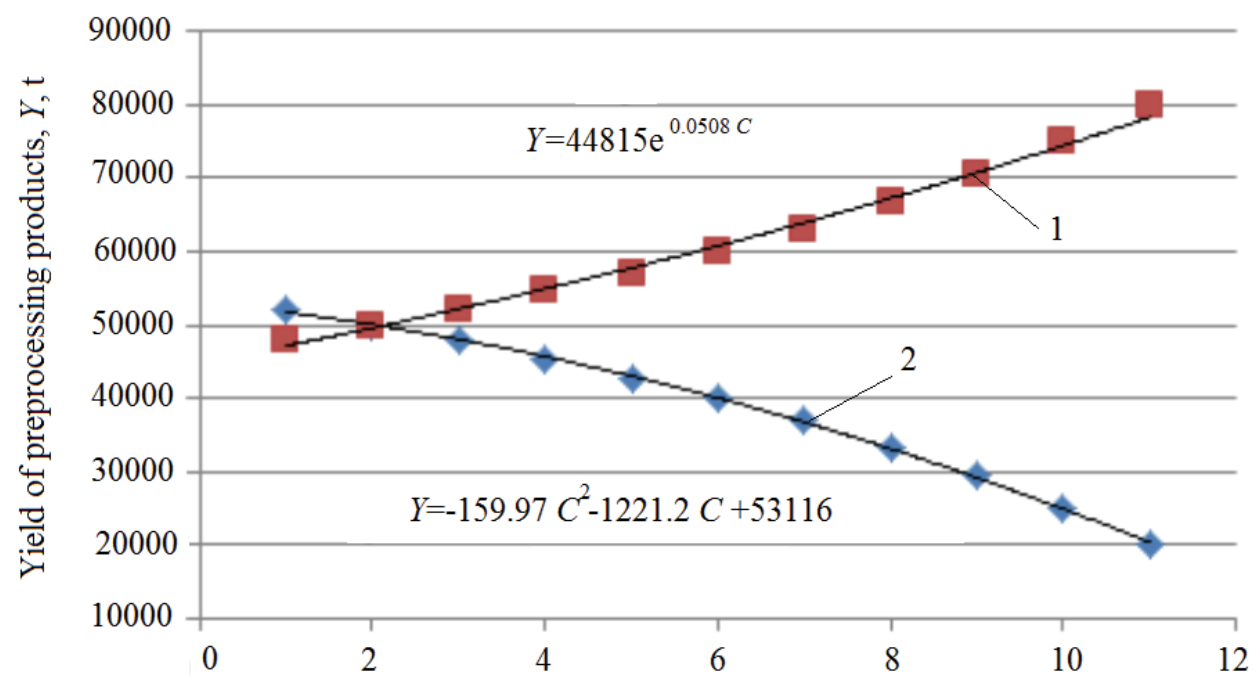

Content of a valuable component in preprocessing wastes, $C, \%$

Fig. 3. Dependence of pre-processing product yield upon the losses of a valuable component and its content in wastes before dressing: 1 - yield of pre-dressing dry wastes, $t ; 2$ - productivity of the preliminary dressing complex as for industrial product, $\mathrm{t}$.

\section{Proposed method helps form mesorelief with the properties close to the natural one}

Open-pit mining is characterized by the destruction of micro- and mesorelief. Mesorelief includes such elements as ravines, basins, hills, slopes, terraces etc. These are the elements that determine peculiarities of microclimate and depth of ground water occurrence and redistribute heat and moisture being essential for the formation of meso- and macrosystems with specific soil features. Mineral extraction results in disturbances of mesorelief due to:

- open-pit mining operations;

- collapse of the land surface during the formation of sinkholes;

- subsidence of the land surface during underground mining of a thick seam or several seams;

- construction of technogenic areas in the form of dumps and sludge collectors; and

- land leveling during construction of a technogenic complex to provide mineral extraction, dressing, and processing.

Service termination of any mining object (open pit, dump, sludge collector) stipulates its recultivation which involves surface leveling (filling of the working), its coating with potential fertile layer, and biological (forestry engineering) stage. However, in this context, relief form, being peculiar for that area before mining operations, is neglected absolutely; that results in the development of numerous processes having negative impact for the environment. That is why, in the process of recultivation with the restoration of previous mesorelief, following should be provided:

- development of basic elements of current natural mesorelief, high-altitude positions, inclination angles of the land surface being formed; 
- layer-by-layer laying or rock types in the dump according to their natural stratigraphic position;

- restoration of porosity in rocks of quaternary deposits by means of layer-by-layer growing of plants while dump forming to provide aquifer recharge.

Mesorelief restoration is a complex and long-term process. A method to form technogenic relief has been proposed; it includes following stages (Fig. 4):

- filling an open pit with the opening rocks down to the depth being less then min level $\mathrm{H}_{\text {min }}$ of previous natural relief $\mathrm{H}_{\text {natural }}$ by the thickness of the formation of sedimentary rocks (filling of potentially fertile layer, aquifer and aquiclude under it);

- formation of aquiclude (clay) at the angle of natural slope $\left(45^{\circ}\right)$ with the opening rocks within the areas where positive relief elements are formed;

- land planning within the fillings with the formation of the required slope angles corresponding to the ones existing before (natural angles), solidification of soil horizon;

- filling of the rocks with water-carrying capacity (sands) of the thickness being close to natural aquifer taking into consideration rock consolidation [4];

- filling of argillaceous rocks to form vertical porosity with mandatory planting [5] (several layers); and

- coating a potentially-fertile soil layer.

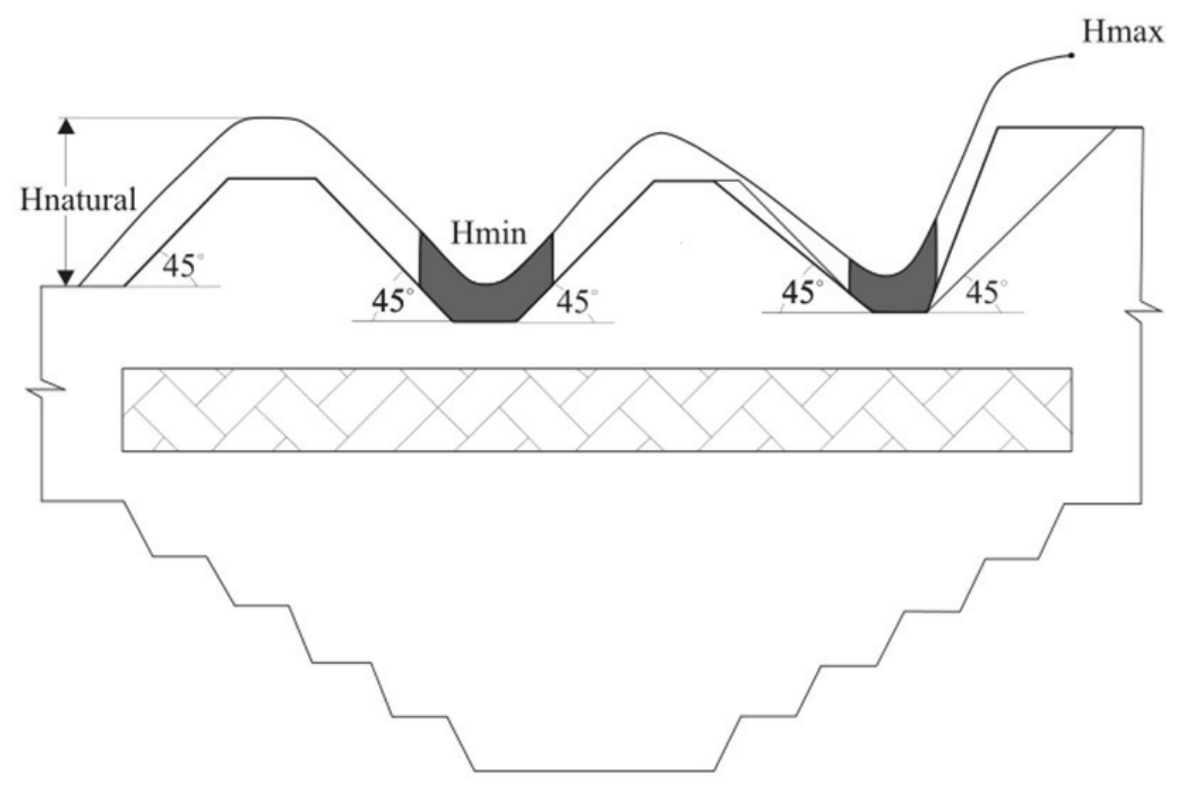

Fig. 4. Scheme of stage-by-stage mesorelief formation.

In terms of parallel deposit mining and mesorelief formation, stage one involves filling of a worked-out areas with opening rocks and planning of a horizontal site with the help of bulldozer down to the depth $\mathrm{H}_{\text {min }}$ being less by the thickness of the formation of sedimentary rocks of previous natural relief $\mathrm{H}_{\text {natural }}[6]$.

After that, fillings within the areas of natural positive relief elements are formed by the height less than $\mathrm{H}_{\max }$ by the thickness of the formation of sedimentary rocks. First, rock (filling) massifs are formed with the help of excavator and motor transport at the angle of natural slope being $45^{\circ}$. Then, the formed filling of opening rocks is planned additionally for the formation of filling slopes so that they correspond to the natural ones. Further layers are coated onto the formed base of the natural massif. 


\section{Conclusions}

A technique to process rock mass from hard-rock technogenic media has been developed; it is aimed at recovering mineral losses and restoring the environment at the territories of mining enterprises by rock mass extraction, processing, and redistribution for land recultivation and landscape restoration.

Classification of dry ore-containing hard rocks of dumps has been elaborated. The classification has become the basis to improve technological scheme of processing rock mass from technogenic media; variants of its application have been emphasized; required facilities along with their productivity have been specified.

Results of the calculations basing upon the proposed processing technique (yield of preprocessing products) have been analyzed. It has helped demonstrate that the yield of industrial product is in polynomial dependence upon the content of magnetite iron in the magnetic product after pre-processing (which is determined by the equipment quality) while tailing yield in terms of the same process is in power dependence.

A method to form mesorelief with the properties close to the natural one has been developed. The method involves restoration of the initial landscape base with the help of opening hard rocks followed by the aquiclude formation with the angles corresponding to the natural ones. After that, water-bearing and potentially-fertile layers are laid.

\section{References}

1 Babii, Ye.V. (2011). Tekhnologiya predobogashcheniya zheleznykh rud v glubokikh karerakh. Kyiv: Naukova dumka

2 Ivanov, O.P. (2005). Karernye gidravlicheskie ekskavatory Hitachi. Mining industry, 2, 53-56

3 Abramov, A.A. (2008). Pererabotka, obogashchenie i kompleksnoe ispolzovanie tverdyh poleznykh iskopaemykh. T 1. Obogatitelnyie protsessy i apparaty. Moskva: Gornaya kniga

4 Chetverik, M.S., Bubnova, Ye.A., Uvarova, L.I. (2005). Vliyanie narusheniya geologicheskoy sredy pri gornykh rabotakh na podtoplenie territoriy. Metallurgical and Mining Industry, 4, 80-83

5 Voron, Ye.A. (2009). Sovershenstvovanie tehnologii rekultivatsii karerov pri ikh dorabotke. Geo-Technical Mechanics, 81, 45-51

6 Malieiev, Ye.V. (2017). Napravleniya razvitiya gornykh rabot po vosstanovleniyu landshafta narushennykh territoriy pri otkrytoy razrabotke gorizontalnykh mestorozhdeniy. Metallurgical and Mining Industry, 4, 63-70 